\title{
Anisotropic Fatigue Modeling of Wrought Magnesium Alloys
}

\author{
Amirhossein Pahlevanpour, Seyed Behzad Behravesh, Hamid Jahed \\ Mechanical and Mechatronics Engineering Department, University of Waterloo \\ Waterloo, Canada
}

\begin{abstract}
The merit of Jahed-Varvani (JV) as an energy-based model and Smith-Watson-Toper (SWT) as a critical plane fatigue model are assessed for three wrought magnesium alloys. The raw data, including the stabilized strain-stress hysteresis loops and strain-life curves, was collected from the literature. The SWT model provided more scattered predictions than the JV model, which suggests that the JV model is more appropriate for fatigue modeling of wrought magnesium alloys, that exhibit anisotropic and asymmetric behavior. A discussion justifies the differences between the predictions of the two models. Eventually, the life of the materials in different directions is predicted by one set of JV parameters, which was previously extracted for AM30 in the transverse direction. The promising results provide supplementary support for the auspicious capability of strain energy density as a damage parameter for wrought magnesium alloys.
\end{abstract}

Keywords- Magnesium; wrought; anisotropy; fatigue; modeling

\section{INTRODUCTION}

The profound impact of the automotive industries on greenhouse gas emission and global warming has led them into light-weighting of their products [1]. Magnesium (Mg) alloys with roughly $35 \%$ and $75 \%$ less density than aluminum and steel, respectively are the lightest available structural metals. This low density and high specific strength of the Mg alloys have made them highly attractive for the transportation industries.

Load-bearing components in vehicles undergo cyclic loadings; therefore, fatigue analysis is inevitable in their design process. However, finding a reliable model to mimic the fatigue behavior of wrought $\mathrm{Mg}$ alloys has been a challenge due to their asymmetric and anisotropic characteristics.

Numerous approaches have been developed and evaluated for the life prediction of wrought $\mathrm{Mg}$ alloys including, the energy-, strain-, stress-, and fracture-mechanic-based models. These efforts can be categorized into either model that consider just one material direction [2]-[6] or the ones that account for the anisotropic characteristic of wrought $\mathrm{Mg}$ alloys [7]-[11].

Lugo et. al [3] developed a microstructure-sensitive model that successfully imitates strain-controlled fatigue experimental observations along the working direction. The model is based on the crack initiation and growth stage constitution, and was justified for three AZ31 initial conditions, i.e., extrusion, rolled plate, and rolled sheet. Castro and Jiang [5] assessed three critical plane approaches: Smith-Watson-Toper (SWT) [12], Fatemi-Socie , and Jiang [14] models, during tensioncompression, torsion, and combined axial-torsion loading on AZ31B along the extrusion direction. The Fatemi-Socie damage parameter provided reasonable fatigue life prediction, but the SWT failed to follow torsion and tension-compression experimental data. The mixed mode cracking was suggested as the source of inaccurate crack orientation prediction for both the SWT and Fatemi-Socie models. The results of Jiang's model were substantiated for all loading conditions, predicting both the fatigue life and the cracking orientation. Xiong and Jiang [2] noticed the SWT parameter's inability to correlate the fatigue life of ZK60 extrusion while scrutinizing its cyclic behavior with intense texture under high strain amplitudes up to $6 \%$ and also stress-controlled condition. Specimen failure under compression for strain amplitudes larger than or equal to $3.5 \%$ was implied to be the cause of the inaccurate SWT predictions, based on the fact that SWT is founded on tensile cracking as the failure mechanism. In contrast, SWT exhibits promising life prediction in the range of $0.2 \%$ to $1.5 \%$ strain amplitudes [6].

Concerning anisotropic fatigue modeling, Lin et al. [4], [8] modified the conventional Basquin's model to account for the mean stress effect and applied the model to hot-rolled AZ91 under cyclic asymmetric stress-controlled loading for rolling and transverse directions. Park et al. [10] evaluated the fatigue life prediction capability of the Ellyin energy-based model [15] in conjunction with stress and plastic strain amplitudes as two damage parameters for rolled AZ31. Loads were applied parallel and perpendicular to the rolling direction. This study concluded that the energy model performs better than the other two models. By employing the modified total strain energy density model proposed by Jahed and Varvani (JV) [16], Roostaei and Jahed [9] achieved satisfactory fatigue life prediction for AM30 extrusion independent of material orientation. They reported that the predicted lives by the SWT model are more scattered and more conservative than the JV model. This behavior was attributed to intricate maximum stress variation at different strain amplitudes [9].

In spite of several attempts to model the fatigue behavior of $\mathrm{Mg}$ alloys, a phenomenological study in search of suitable fatigue criterion capable of capturing the asymmetric and anisotropic behavior of wrought $\mathrm{Mg}$ alloys is still lacking. This paper examines SWT and JV models for anisotropic life 
prediction of wrought $\mathrm{Mg}$ alloys using data available in the literature. Then, the idea of employing a single set of parameters for life estimation of wrought $\mathrm{Mg}$ alloys in various loading directions is evaluated. For this study, the set of parameters for the JV model, already been extracted for AM30 extrusion in the transverse direction, was utilized to predict the fatigue life of AZ31B and AZ80 in different directions.

\section{EXPERIMENTAL SETUP}

Only a few published works present the strain-life curves and stabilized hysteresis loops for wrought $\mathrm{Mg}$ alloys in different directions. The studies conducted by $\mathrm{L}$. $\mathrm{Wu}$ et al. on rolled AZ31B-H24 [17], F. Lv et al. on rolled AZ31B [11], Xiong and Jiang on rolled AZ80 [7] and Roostaei and Jahed on AM30 extrusion [9] are among those few published results. The details of the investigated materials are presented in Table. I. In what follows, rolling direction (RD) will be assigned as the reference direction for AZ31-H24, AZ31B, and AZ80 in two fatigue models and the life in the other directions will be predicted based on the reference parameters.

TABLE I. INVESTIGATED WROUGHT MG ALLOYS

\begin{tabular}{c|c|c|c|c|c} 
Material & Process & Directions & $\begin{array}{c}\text { Strain } \\
\text { ratio }\end{array}$ & Environment & Reference \\
\hline $\begin{array}{c}\text { AZ31B- } \\
\text { H24 }\end{array}$ & Rolled & $\begin{array}{c}\text { Rolling (RD) } \\
\text { Transverse (TD) } \\
\text { Normal (ND) }\end{array}$ & -1 & Ambient & [17] \\
\hline AZ31B & Rolled & $\begin{array}{c}\text { Rolling (RD) } \\
\text { Normal (ND) }\end{array}$ & -1 & Ambient & {$[11]$} \\
\hline AZ80 & $\begin{array}{c}\text { Hot- } \\
\text { rolled }\end{array}$ & $\begin{array}{c}\text { Rolling (RD) } \\
\text { Normal (ND) } \\
\text { to normal (ND30) } \\
60^{\circ} \text { to normal (ND60) }\end{array}$ & -1 & Ambient & [7] \\
\hline AM30 & Extrusion & $\begin{array}{c}\text { Extrusion (ED) } \\
\text { Transverse (TD) }\end{array}$ & -1 & Ambient & [9]
\end{tabular}

\section{MODELING}

\section{A. Smith-Watson-Topper (SWT)}

SWT is a critical plane fatigue model, that takes into account mean stress effect through the maximum stress term as shown in (1) $[12]$ :

$$
S W T=\sigma_{n, \max } \frac{\Delta \varepsilon_{1}}{2}
$$

where $\sigma_{n, \max }$ and $\Delta \varepsilon_{1}$ are the maximum normal stress and the principal strain range on the principal strain plane, respectively. The SWT parameter has been correlated to the fatigue life of $\mathrm{Mg}$ alloys by either [2], [6],

$$
\left(S W T-F P_{0}\right)^{v} N_{f}=D
$$

where $F P_{0}, v$, and $D$ are fitting coefficients; or by CoffinManson parameters [9], [18]-[20] employed in this study as well,

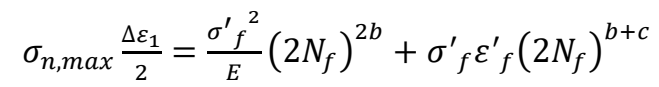

where:

$\sigma_{f}^{\prime}$ : Fatigue strength coefficient

$\varepsilon_{f}^{\prime}$ : Fatigue toughness coefficient

$b$ : Fatigue strength exponent

$c$ : Fatigue toughness exponent

and $E$ is the modulus of elasticity. The parameters in the SWT model are essentially the same as those in the Coffin-Manson model [21], [22],

$$
\frac{\Delta \varepsilon}{2}=\frac{{\sigma_{f}^{\prime}}_{E}}{E}\left(2 N_{f}\right)^{b}+\varepsilon_{f}^{\prime}\left(2 N_{f}\right)^{c}
$$

Therefore, the parameters are obtained by the decomposition of strain range into elastic and plastic strain ranges, as shown in Fig. 1.

The Coffin-Manson parameters for the three different materials were extracted in the reference direction, RD, and are tabulated in Table. II. Adopting the SWT criteria and using the Coffin-Manson parameters, fatigue lives in all directions were calculated using a single set of parameters per material. Fig. 2 depicts the predicted life versus the experimental life for the three materials in various directions. The solid line denotes the perfect estimation, whereas the dashed and dashed-dot lines enclose the factor of 2 and 3 boundaries, respectively.

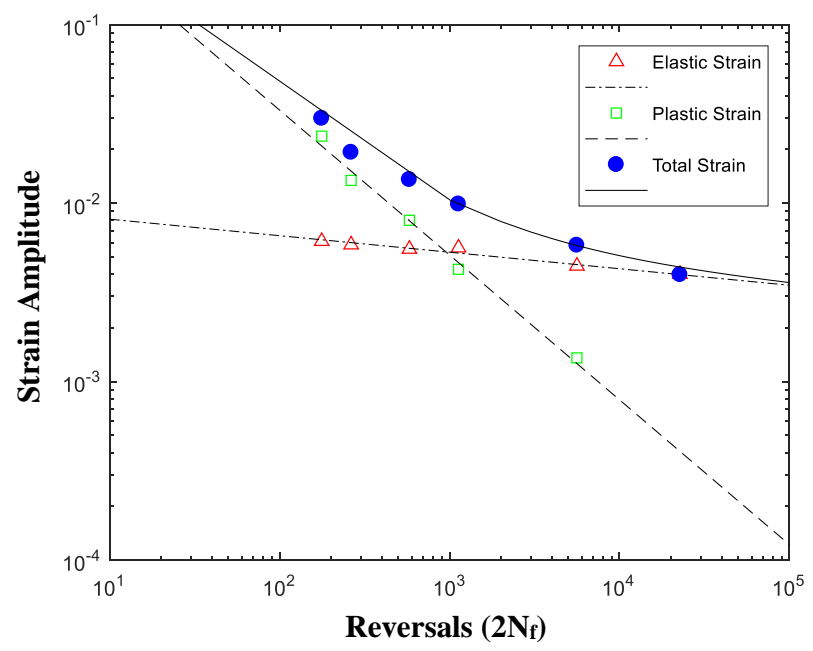

Figure 1. Strain range decomposition for the Coffin-Manson model; the typical result for AZ31B-H24 along RD

TABLE II. COFFIN-MANSON PARAMETERS ALONG RD FOR INVESTIGATED MG ALLOYS

\begin{tabular}{c|c|c|c}
\multicolumn{2}{r|}{ AZ31-H24 } & AZ31B & AZ80 \\
\hline $\boldsymbol{\sigma}_{\boldsymbol{f}}^{\prime}(\mathbf{M P a})$ & 442.49 & 749.75 & 422.07 \\
\hline $\boldsymbol{\varepsilon}_{\boldsymbol{f}}^{\prime}$ & 1.393 & 0.185 & 0.103 \\
\hline $\boldsymbol{b}$ & -0.092 & -0.179 & -0.071 \\
\hline $\boldsymbol{c}$ & -0.811 & -0.604 & -0.545
\end{tabular}


As expected, the life estimation for RD in all materials is satisfactory, demonstrating that the mathematical fitting was conducted correctly. However, the fatigue lives in other directions were overpredicted for AZ31B-H24 and AZ80, and underpredicted in AZ31B. In particular, the predicted life deviated from the factor of 3 bound for ND samples of AZ80 and AZ31-H24. This deviation is more intense for AZ80 in ND30 specimens, which will be discussed later. In contrast, the predicted lives for AZ31B, being conservative, fall within the factor of 2 bound lines.
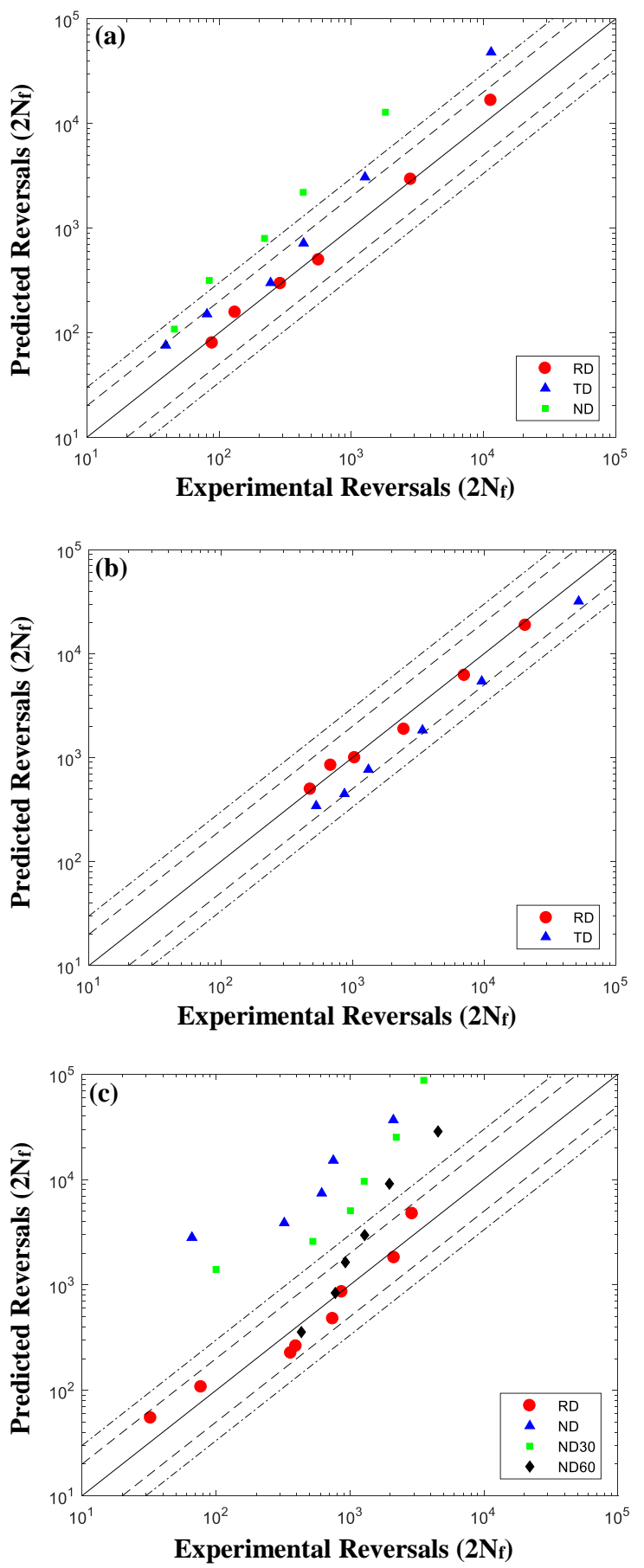

Figure 2. SWT fatigue life prediction for a) AZ31B-H24, b) AZ31B, and c) AZ80

\section{B. Jahed-Varvani (JV)}

The invariant nature of energy makes energy-based fatigue models appropriate candidates for $\mathrm{Mg}$ alloys with asymmetric and anisotropic characteristics, and they have been employed for the life estimation of many Mg alloys [5], [9], [10], [18], [20], [23]-[27]. Jahed and Varvani [16] employed total strain energy density as the damage parameter by incorporating energy-based fatigue properties,

$$
\underbrace{\Delta E}=\Delta E_{e}^{+}+\Delta E_{p}
$$

JV parameter

where $\Delta E_{p}$ is plastic strain energy density and defined as the area enveloped by the stabilized hysteresis loops and $\Delta E_{e}^{+}$is the positive elastic strain energy density, and is calculated as follows:

$$
\Delta E_{e}^{+}=\frac{\sigma_{\max }^{2}}{2 E}
$$

where $\sigma_{\max }$ is the maximum tensile stress of the stabilized hysteresis loop. The JV parameter is correlated to the life through:

$$
J V=E_{e}^{\prime}\left(2 N_{f}\right)^{B}+E_{f}^{\prime}\left(2 N_{f}\right)^{C}
$$

where

$E_{e}^{\prime}:$ Fatigue strength coefficient

$E_{f}^{\prime}$ : Fatigue toughness coefficient

$B$ : Fatigue strength exponent

$C$ : Fatigue toughness exponent

are the material constants extracted from the curves fitted to the elastic and plastic strain energy versus life, as depicted in Fig. 3. This figure presents the typical strain energy decomposition for AZ31B-H24 along the reference direction, RD. The JV model parameters for the three different materials along $\mathrm{RD}$ are summarized in Table. III.

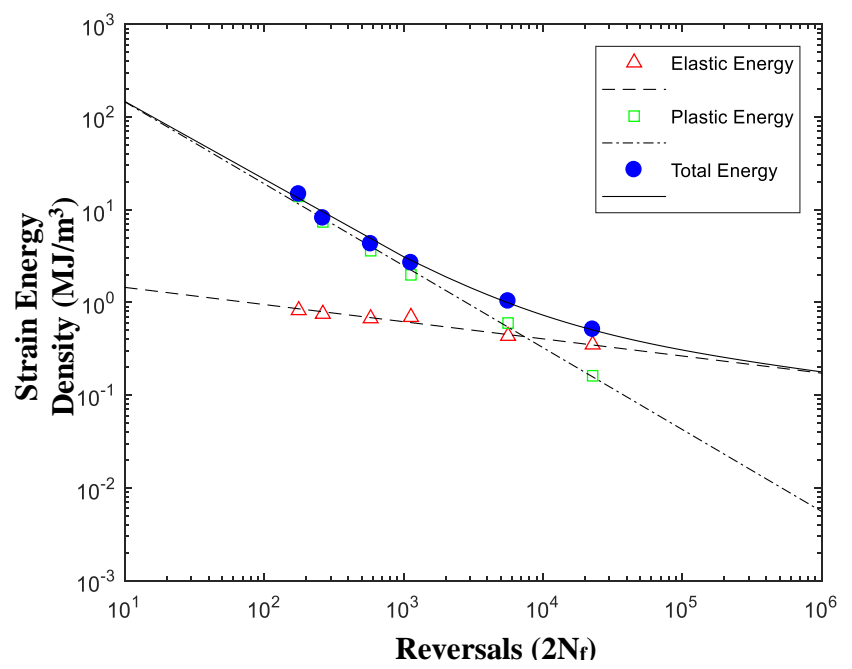

Figure 3. Decomposition of strain energy for the JV model; the typical result for AZ31B-H24 along RD 
TABLE III. JV MODEL PARAMETERS ALONG RD FOR DIFFERENT MG ALLOYS

\begin{tabular}{c|c|c|c} 
& AZ31-H24 & AZ31B & AZ80 \\
\hline $\boldsymbol{E}^{\prime}{ }_{\boldsymbol{e}}\left(\mathbf{M J} / \mathbf{m}^{\mathbf{3}}\right)$ & 2.225 & 6.387 & 2.024 \\
\hline $\boldsymbol{E}_{\boldsymbol{f}}{ }_{\boldsymbol{f}}\left(\mathbf{M J} / \mathbf{m}^{\mathbf{3}}\right)$ & 1115.85 & 746.37 & 64.26 \\
\hline $\boldsymbol{B}$ & -0.185 & 0.357 & -0.142 \\
\hline $\boldsymbol{C}$ & -0.884 & 0.911 & -0.598
\end{tabular}

By employing the JV model in conjunction with a single set of parameters per material, fatigue lives in different directions were predicted and plotted against the experimental lives in Fig. 4. The vast majority of data points for all subject materials are bounded within the factor of 3 , independent of loading direction. Modest overprediction is perceived for AZ31-H24; in contrast, the lives congregate tightly about the ideal estimation with slight conservative predictions for AZ31B. The life of AZ80 samples in ND is highly overpredicted at the two extremes of the experimental life range, whereas estimated life is almost uniformly distributed over and under the ideal prediction in RD, ND30, and ND60 directions, besides laying within the bounds of \pm 3 factor. The observed results demonstrate the competency of the JV model for anisotropic and asymmetric wrought $\mathrm{Mg}$ alloys.
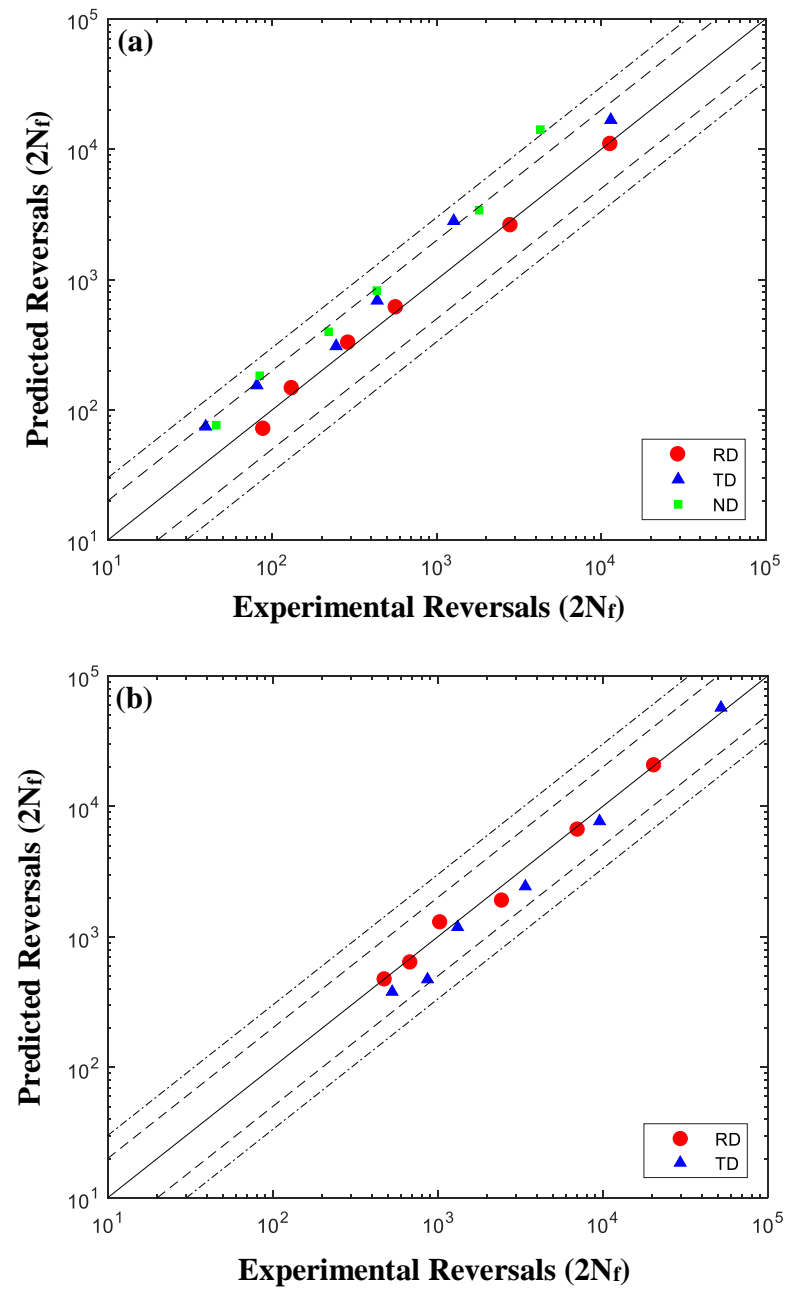

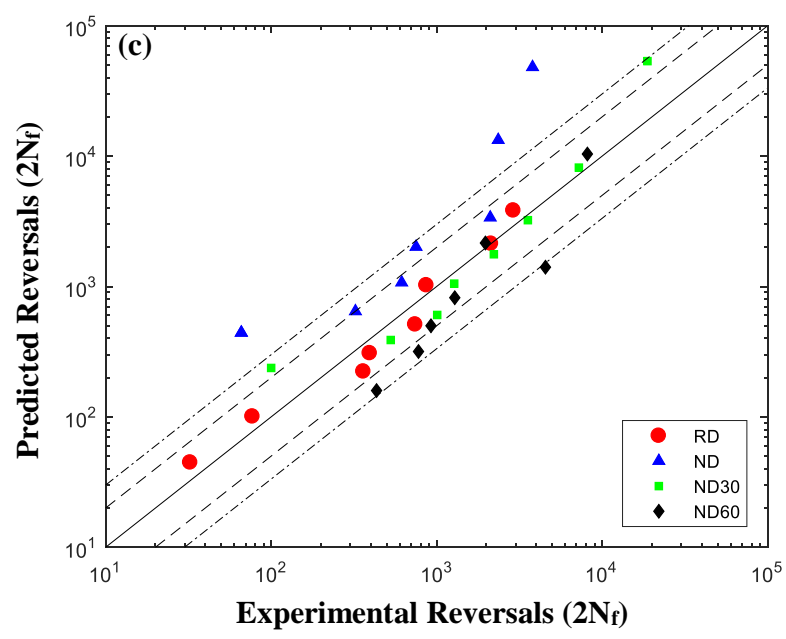

Figure 4. JV fatigue life prediction for a) AZ31B-H24, b) AZ31B, and c) AZ80

\section{Discussion}

In general, the two models provide a good fatigue-life prediction performance. The SWT model's shortcomings for some of the fatigue data are attributed to two factors [2]:

1. Many wrought $\mathrm{Mg}$ alloys show nonlinear elastoplastic strain responses in the strain amplitudes higher than $1 \%$ which could not be captured by linear Coffin-Manson fitting embedded in the employed SWT method [2], [7], [11].

2. Deformation mechanism alternation from slip to twinning/detwinning at some certain strain level introduces a kink point in the strain-life curve [2], [5], [6], which can considerably affect the fatigue resistance. Also, the change in the deformation mechanism is reflected in the hysteresis-loop shape and the enclosed area, which is not accounted for in the SWT model.

To further investigate the life prediction of SWT under large strain amplitudes, the stabilized hysteresis loops for AZ31B$\mathrm{H} 24$ under $\varepsilon_{\mathrm{a}}=1.4 \%$ in different directions are provided in Fig. 5 . The life reported for these tests in all directions are roughly the same and equal to 250 cycles [17]; however, their hysteresis loops are substantially different. Also, a significant mean stress is developed that is not accounted for, in the life model parameters of SWT. Table. IV compares the JV and its components in addition to SWT damage parameter for RD and ND. In spite of the fact that both RD and ND samples had nearly the same life, the SWT parameter values in these directions differ by $42 \%$, whereas the difference for the JV parameter is $14 \%$. The pronounced elastic strain divergence in comparison with plastic strain could explain the SWT's unsatisfactory life prediction in HCF where the elastic energy is dominant. The minimum difference belongs to the plastic portion of the strain energy density, which has been proven to be a robust damage parameter for the LCF regime [7], although its precision will 
decrease in the HCF regime, where less energy is dissipated in each cycle.

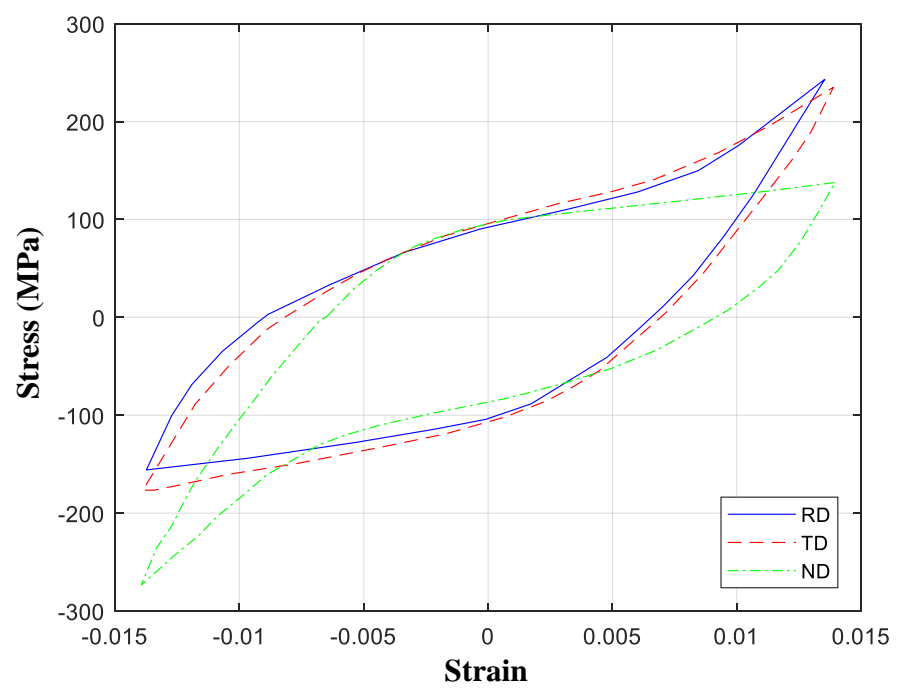

Figure 5. AZ31B-H24 stabilized hysteresis loops for $1.4 \%$ strain

TABLE IV. AZ31B-H24 FATIGUE MODEL PARAMETERS FOR AZ31B-H24 UNDER $\varepsilon_{\mathrm{A}}=1.4 \%$

\begin{tabular}{c|c|c|c} 
& RD & ND & $\begin{array}{c}\text { Difference } \\
(\mathbf{\%})\end{array}$ \\
\hline $\begin{array}{c}\text { Elastic Energy } \\
\text { Density }\end{array}$ & 0.672 & 0.215 & 68.0 \\
\hline $\begin{array}{c}\text { Plastic Energy } \\
\text { Density }\end{array}$ & 3.612 & 3.475 & 3.8 \\
\hline JV & 4.284 & 3.690 & 13.9 \\
\hline $\boldsymbol{\varepsilon}_{\text {elastic }}$ & 0.0055 & 0.0031 & 43.6 \\
\hline $\boldsymbol{\varepsilon}_{\text {plastic }}$ & 0.0085 & 0.0109 & 28.2 \\
\hline SWT & 3.292 & 1.921 & 41.6
\end{tabular}

In order to evaluate JV as a universal fatigue model for $\mathrm{Mg}$ alloys, the JV parameters extracted for AM30 in TD, which are tabulated in Table. V [9], were employed to predict the life of the three materials under investigation. Fig. 6 shows predicted versus experimental fatigue lives, where most of the points are condensed within the factor of 3 boundaries. The present research further supports the findings of previous studies [5], [9], [10], [18], [20], [23]-[26] in which the strain energy density with its corresponding life model is an appropriate damage parameter for wrought $\mathrm{Mg}$ alloys with asymmetric and anisotropic behavior.

TABLE V. JV PARAMETERS FOR AM30 EXTRUSION ALONG TD [9]

\begin{tabular}{c|c}
$\boldsymbol{E}_{\boldsymbol{e}}^{\prime}\left(\mathbf{M J} / \mathbf{m}^{\mathbf{3}}\right)$ & 2.995 \\
\hline $\boldsymbol{E}_{\boldsymbol{f}}^{\prime}\left(\mathbf{M J} / \mathbf{m}^{\mathbf{3}}\right)$ & 1710.690 \\
\hline $\boldsymbol{B}$ & -0.281 \\
\hline $\boldsymbol{C}$ & -0.975
\end{tabular}

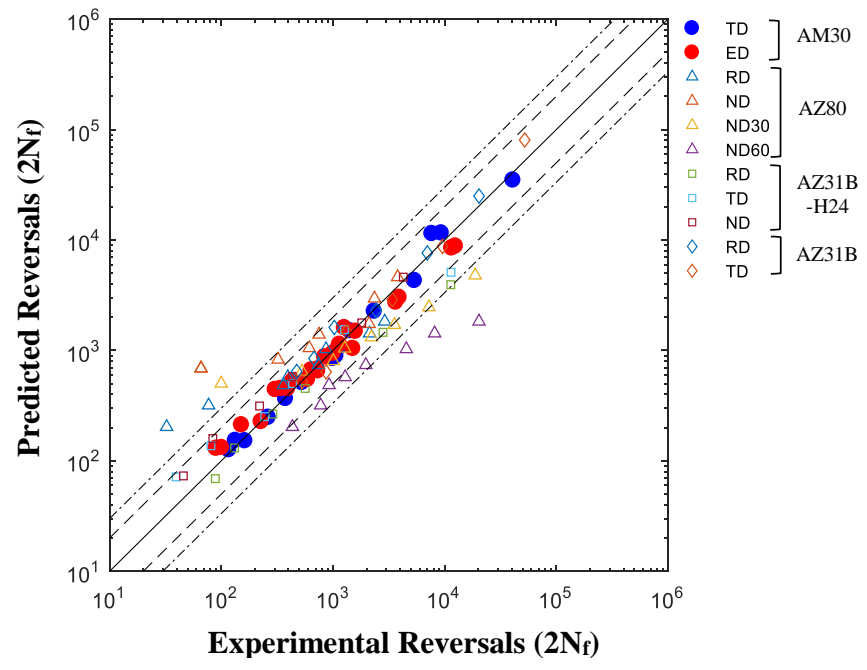

Figure 6. JV fatigue life estimation

\section{REFERENCES}

[1] H. Friedrich, "Research for a 'new age of magnesium' in the automotive industry," J. Mater. Process. Technol., vol. 117, pp. 276-281, 2001.

[2] Y. Xiong and Y. Jiang, "Fatigue of ZK60 magnesium alloy under uniaxial loading," Int. J. Fatigue, vol. 64, pp. 74-83, 2014.

[3] M. Lugo, J. B. Jordon, K. N. Solanki, L. G. Hector, J. D. Bernard, A. A. Luo, and M. F. Horstemeyer, "Role of different material processing methods on the fatigue behavior of an AZ31 magnesium alloy," Int. J. Fatigue, vol. 52, pp. 131-143, 2013.

[4] X. M. Chen, Y. C. Lin, and J. Chen, "Low-cycle fatigue behaviors of hotrolled AZ91 magnesium alloy under asymmetrical stress-controlled cyclic loadings," J. Alloys Compd., vol. 579, pp. 540-548, 2013.

[5] F. Castro and Y. Jiang, "Fatigue life and early cracking predictions of extruded AZ31B magnesium alloy using critical plane approaches," Int. J. Fatigue, vol. 88, pp. 236-246, 2016.

[6] Q. Yu, J. Zhang, Y. Jiang, and Q. Li, "An experimental study on cyclic deformation and fatigue of extruded ZK60 magnesium alloy," Int. J. Fatigue, vol. 36, no. 1, pp. 47-58, 2012.

[7] Y. Xiong and Y. Jiang, "Cyclic deformation and fatigue of rolled AZ80 magnesium alloy along different material orientations," Mater. Sci. Eng. A, vol. 677, pp. 58-67, 2016

[8] Y. C. Lin, X.-M. Chen, Z.-H. Liu, and J. Chen, "Investigation of uniaxial low-cycle fatigue failure behavior of hot-rolled AZ91 magnesium alloy," Int. J. Fatigue, vol. 48, no. C, pp. 122-132, 2013.

[9] A. A. Roostaei and H. Jahed, "Role of loading direction on cyclic behaviour characteristics of AM30 extrusion and its fatigue damage modelling," Mater. Sci. Eng. A, vol. 670, pp. 26-40, 2016.

[10] S. H. Park, S. G. Hong, W. Bang, and C. S. Lee, "Effect of anisotropy on the low-cycle fatigue behavior of rolled AZ31 magnesium alloy," Mater. Sci. Eng. A, vol. 527, no. 3, pp. 417-423, 2010.

[11] F. Lv, F. Yang, Q. Q. Duan, Y. S. Yang, S. D. Wu, S. X. Li, and Z. F. Zhang, "Fatigue properties of rolled magnesium alloy (AZ31) sheet: Influence of specimen orientation," Int. J. Fatigue, vol. 33, no. 5, pp. 672682, 2011.

[12] Kn. Smith, T. H. Topper, and P. Watson, "A stress-strain function for the fatigue of metals(Stress-strain function for metal fatigue including mean stress effect)," J. Mater., vol. 5, no. January 1970, pp. 767-778, 1970.

[13] A. Fatemi and D. F. Socie, "A critical plane approach to multiaxial fatigue damage including out-of-phase loading," Fatigue Fract. Eng. Mater. Struct., vol. 11, no. 3, pp. 149-165, 1988.

[14] Y. Jiang, "Fatigue criterion for general multiaxial loading," Fatigue Fract. Eng. Mater. Struct., vol. 23, no. 1, pp. 19-32, 2000. 
[15] F. Ellyin, "Fatigue Damage, Crack Growth and Life Prediction," p. XVI470, 1996.

[16] H. Jahed and a. Varvani-Farahani, "Upper and lower fatigue life limits model using energy-based fatigue properties," Int. J. Fatigue, vol. 28, no. 5-6, pp. 467-473, 2006.

[17] L. Wu, S. R. Agnew, Y. Ren, D. W. Brown, B. Clausen, G. M. Stoica, H. R. Wenk, and P. K. Liaw, "The effects of texture and extension twinning on the low-cycle fatigue behavior of a rolled magnesium alloy, AZ31B," Mater. Sci. Eng. A, vol. 527, no. 26, pp. 7057-7067, 2010.

[18] D. Toscano, S. K. Shaha, B. Behravesh, H. Jahed, and B. Williams, "Effect of forging on the low cycle fatigue behavior of cast AZ31B alloy," Mater. Sci. Eng. A, vol. 706, no. August, pp. 342-356, 2017.

[19] A. Gryguc, S. K. Shaha, S. B. Behravesh, H. Jahed, M. Wells, B. Williams, and X. Su, "Monotonic and cyclic behaviour of cast and castforged AZ80 Mg," Int. J. Fatigue, vol. 104, pp. 136-149, 2017.

[20] J. Albinmousa and H. Jahed, "Multiaxial effects on LCF behaviour and fatigue failure of AZ31B magnesium extrusion," Int. J. Fatigue, vol. 67, pp. 103-116, 2014.

[21] J. F. Tavernelli and L. F. Coffin, "Experimental Support for Generalized Equation Predicting Low Cycle Fatigue," J. Basic Eng., vol. 84, no. 4, p. 537, 1962.
[22] S. Manson, "Discussion on JF. Tavernelli and LF. Coffin "Experimental support for generalized equation predicting low cycle fatigue"," J. Basic Eng., vol. 84, no. 4, p. 537, 1962.

[23] S. H. Park, S.-G. Hong, J. Yoon, and C. S. Lee, "Influence of loading direction on the anisotropic fatigue properties of rolled magnesium alloy," Int. J. Fatigue, vol. 87, pp. 210-215, 2016.

[24] A. Gryguc, S. K. Shaha, H. Jahed, M. Wells, B. Williams, and J. McKinley, "Tensile and fatigue behaviour of as-forged AZ31B extrusion," Frat. ed Integrita Strutt., vol. 10, no. 38, pp. 251-258, 2016.

[25] J. Albinmousa, H. Jahed, and S. Lambert, "Cyclic behaviour of wrought magnesium alloy under multiaxial load," Int. J. Fatigue, vol. 33, no. 8, pp. 1127-1139, 2011.

[26] F. Castro and Y. Jiang, "Fatigue of extruded AZ31B magnesium alloy under stress- and strain-controlled conditions including step loading," Mech. Mater., vol. 108, pp. 77-86, 2017.

[27] H. Jahed and J. Albinmousa, "Multiaxial behaviour of wrought magnesium alloys - A review and suitability of energy-based fatigue life model," Theor. Appl. Fract. Mech., vol. 73, pp. 97-108, 2014. 